\title{
Risk Groups Defined by Recursive Partitioning Analysis of Patients with Colorectal Adenocarcinoma Treated with Colorectal Resection
}

Yun-Jau Chang ${ }^{1,2,3}$, Li-Ju Chen $^{1,4}$, Yao-Jen Chang ${ }^{5}$, Kuo-Piao Chung $^{1 *}$ and Mei-Shu Lai ${ }^{6}$

\begin{abstract}
Background: To define different prognostic groups of surgical colorectal adenocarcinoma patients derived from recursive partitioning analysis (RPA).

Methods: Ten thousand four hundred ninety four patients with colorectal adenocarcinoma underwent colorectal resection from Taiwan Cancer Database during 2003 to 2005 were included in this study. Exclusion criteria included those patients with stage IV disease or without number information of lymph nodes. For the definition of risk groups, the method of classification and regression tree was performed. Main primary outcome was 5-year cancerspecific survival.

Results: We identified six prognostic factors for cancer-specific survival, resulting in seven terminal nodes. Four risk groups were defined as following: Group 1 (mild risk, 1,698 patients), Group 2 (moderate risk, 3,129 patients), Group 3 (high risk, 4,605 patients) and Group 4 (very high risk, 1,062 patients). The 5-year cancer-specific survival for Group $1,2,3$, and 4 was $86.6 \%, 62.7 \%, 55.9 \%$, and $36.6 \%$, respectively $(p<0.001)$. Hazard ratio of death was $2.13,5.52$ and 10.56 (95\% confidence interval 1.74-2.60, 4.58-6.66 and 8.66-12.9, respectively) times for Group 2, 3, and 4 as compared to Group 1. The predictive capability of these grouping was also similar in terms of overall and progression-free survival.
\end{abstract}

Conclusion: The use of RPA offered an alternative grouping method that could predict the survival of patients who underwent surgery for colorectal adenocarcinoma.

Keywords: Recursive Partitioning Analysis, Colorectal Cancer, Survival Analysis

\section{Background}

Adenocarinoma is the most commonly seen malignancy of colon and rectum, which ranks the third leading cause for cancer death both in USA and Taiwan as well as the fourth cause worldwide [1]. Although the diagnostic instrument and treatment modality had made a huge progress leap in recent decade, the survival outcome of colorectal cancer patients didn't keep up the identical or similar pace by multiple factors [2]. Clinical practice guideline and performance measurement came up with the impetus to formalize clinicians' daily practice and possibly improve patients' survival thereafter. The most

\footnotetext{
* Correspondence: kpchung@ntu.edu.tw

'Graduate Institute of Health Policy and Management, College of Public Health, National Taiwan University, Taipei, Taiwan

Full list of author information is available at the end of the article
}

frequently accepted prognostic factor is TNM staging system, but for real world, there are many factors beyond TNM staging that can confound the patients' survival. Hence a risk group study may hopefully yield substantial information that is succinct and easily understood by researchers, providers, practitioners, patients, and even the policy makers to make appropriate choices.

Recursive partitioning analysis (RPA), a method of classification, was initially described by the Radiation Therapy Oncology Group and was intended to provide a way that divide patients into homogenous groups based on the length of survival [3]. Advantages of this method include not only making fewer modeling assumptions, but also establishing procedure that adapts to missing values through the use of surrogate measures [4]. Currently,
C Biomed Central 
sophisticated computer system offers a good solution possible for these tedious computations.

In this study, the main objective was to assign different prognostic groups with regard to cancer-specific survival derived from RPA among patients with newly diagnosed colorectal adenocarcinoma who underwent colorectal resection for cancer surgery from a population-based data. We also compared these groups regarding three different types of survival (overall survival, progression-free survival and cancer-specific survival)

\section{Methods}

\section{Study population}

This study consisted of a consecutive series of 15,731 patients who were newly diagnosed with colorectal cancer during the period of January 2003 to December 2005 from a population-based database, Taiwan Cancer Database, and linkage with TCDB to 2003-2009 Death Registries. Taiwan Cancer Database (TCDB) was a nationwide program that accounted for about $60 \%$ of patients with six cancer types (breast, colon, liver, lung, cervical and buccal cancer) per year and served as a good source for academic research [1]. We identified colorectal cancer patients newly registered into the TCDB according to ICD-O-3 (International Classification of Diseases for Oncology, third revision) code C18.0 (cecum)-C21.8 (rectum). Exclusion criteria included patients with stage IV, cancer at anus, pathologic report beyond adenocarcinoma, without colorectal resection, and unknown specification of cancer stage as well as unavailability of lymph node information. We also excluded patients whose survival status cannot be verified as of December 31, 2009. This study was approved by the institutional review board (IRB) at College of Public Health, National Taiwan University.

\section{Study outcomes}

The primary end point was 5-year survival including overall survival, progression-free survival and disease-specific survival. Overall survival rate denoted the percentage of patients who were still alive for a certain period of time after surgery for colorectal cancer. Progression-free survival rate denoted the percentage of patients who were still without any signs of colorectal cancer for a certain period of time after surgery for colorectal cancer. Cancer-specific survival rate (or disease-specific survival) referred to the percentage of patients who had not died from colorectal cancer or metastasis for a certain period of time after surgery for colorectal cancer. All survival rates were calculated from the day of surgery (colorectal resection).

\section{Statistical analysis}

We used classification and regression (CRT) method, developed for binominal data, in the analysis of RPA [5]. This technique is a nonparametric methodology that creates a decision tree with respect to prognostic factors and their interactions which are most important in determining the outcome. A parent node would split into child nodes that are as homogenous as possible to dependent variables. The split also followed the rules that the corresponding cut-off points with the minimal $\mathrm{P}$ value, provided the minimal $P$ value was $<=0.0001$ and that the number of patients within the child node was at least 50. Then a tree-based model composed of nodes was fashioned by recursively partitioning the study cohort. During the RPA process of this study, a set of variables had been evaluated as prognostic factors, including: age (split at 50,60, 70 years), gender (male vs. female), comorbidity (Deyo's modified version of the Charlson comorbidity index - CCI) [6], tumor location (colon, sigmoid, rectum), number of lymph nodes retrieved and examined (continuous), distance of surgical margin to tumor (positive or $<0.2 \mathrm{~cm}, 0.2 \mathrm{~cm}$ to $1 \mathrm{~cm},>1 \mathrm{~cm}$ ), depth of tumor invasion (submucosa, muscularis propria, into subserosa, invasion to other organs), pathological tumor size $(0-2 \mathrm{~cm}, 2-3 \mathrm{~cm}, 3-4 \mathrm{~cm}, 4-6 \mathrm{~cm},>6 \mathrm{~cm})$, histopathology (adenocarcinoma vs. mucinous adenocarcinoma or signet ring cell adenocarcinoma), TNM stages (stage I, stage II, stage III, based on the classification of sixth edition of American Joint Commission on Cancer Staging Manual), fluorouracil-based chemotherapy (yes vs. no), radiotherapy (yes vs. no). Because CRT did not stop in the middle of the tree-growing process, we pruned tree to avoid overfitting by setting maximum difference in risk as 1 . Also for validation, we randomly assigned 50\% cohort as training sample (for model building) and other $50 \%$ as test sample (for model validation).

After CRT algorithm, several terminal nodes were created and these nodes would be combined into a group when the significance level of comparison between two terminal nodes was $>0.05$. With these RPA group, we used paired t-test to determine whether the 5-year overall, 5 -year progression-free and 5-year disease-specific survival differed significantly between these RPA groups. The Kaplan-Meier method was used to calculate cumulative survival. Differences in cumulative survival between two groups were tested by the log-rank test. All $P$ values were two sided and a $\mathrm{P}<0.05$ was considered statistically significant. We used PASW Statistics 18 as statistic software for all of the analyses reported in this study.

\section{Results}

Of 15,731 newly diagnosed colorectal cancer patients, there were 12,860 patients who had undergone colorectal resection for colorectal cancer (Figure 1). Among them, 2,126 patients (16.7\%), 4,008 patients (31.5\%), 4,383 patients $(34.4 \%)$ and 2,227 patients $(17.5 \%)$ presented with stage I, stage II, stage III and stage IV disease, respectively. We excluded 2,227 patients with stage IV 


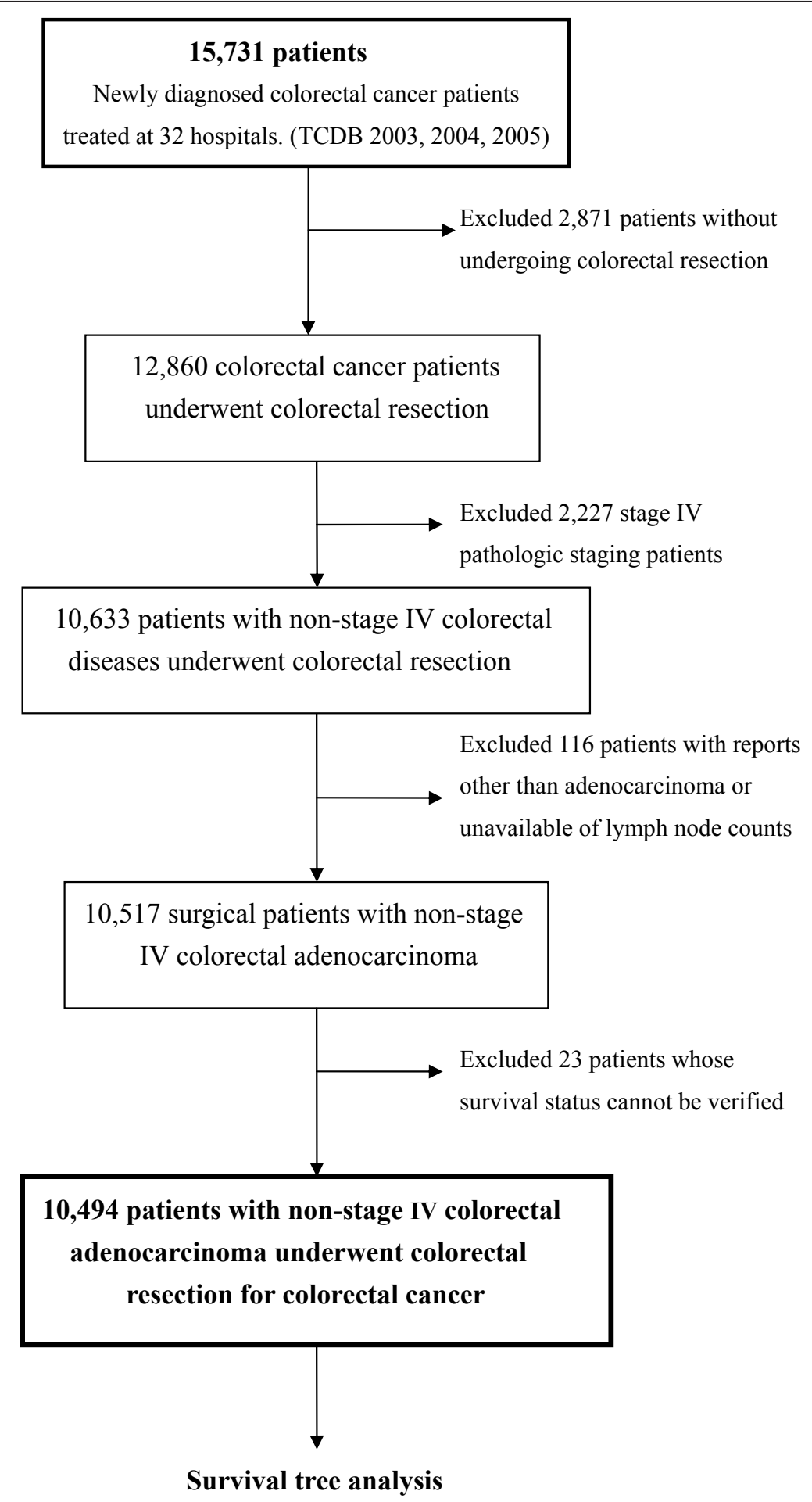

Figure 1 Schema of patients'enrollment in this study. (TCDB: Taiwan Cancer Database).

disease, 116 patients with pathological report other than adenocarcinoma or unavailable of lymph node counts, and 23 patients whose survival status could not be verified. The resulting cohort, 10,494 patients, who underwent colorectal resection in thirty-two major hospitals or cancer centers were eligible to enter into this survival tree analysis. The majority of patients were older than 70 years of age $(39.8 \%, 4,173 / 10,494)$ and comorbidity indexes were $>=3(52.5 \%, 5,509 / 10,494)$ (Table 1). Among these patients, male patients were slightly more 
Table 1 Demographic and treatment of colorectal adenocarcinoma patients

\begin{tabular}{|c|c|c|c|c|c|}
\hline & $\mathrm{N}$ & $\begin{array}{l}\text { Cumulative survival (\%) not died of cancer at } \\
\text { 5-years }\end{array}$ & $\mathrm{HR}$ & $\begin{array}{l}95.0 \% \\
\mathrm{Cl}\end{array}$ & Significance ${ }^{*}$ \\
\hline Gender & & & & & 0.000 \\
\hline male & 5,937 & $69 \%$ & 1.00 & & \\
\hline female & 4,557 & $73 \%$ & 0.86 & $0.80-0.93$ & \\
\hline AGE & & & & & 0.000 \\
\hline$>50 \mathrm{yrs},<=60 \mathrm{yrs}$ & 1,994 & $76 \%$ & 1.00 & & \\
\hline$<50$ yrs & 1,516 & $75 \%$ & 1.19 & $1.03-1.38$ & \\
\hline$>60 \mathrm{yrs},<=70 \mathrm{yrs}$ & 2,811 & $73 \%$ & 1.14 & $1.01-1.30$ & \\
\hline$>70$ yrs & 4,173 & $64 \%$ & 1.64 & $1.46-1.84$ & \\
\hline Co-morbidity (CCl) & & & & & 0.000 \\
\hline $\mathrm{CCl}=0+1$ & 952 & $87 \%$ & 1.00 & & \\
\hline $\mathrm{CCl}=2$ & 4,033 & $78 \%$ & 1.51 & $1.24-1.85$ & \\
\hline $\mathrm{CCl}>=3$ & 5,509 & $62 \%$ & 1.92 & $1.58-2.33$ & \\
\hline Tumor location & & & & & 0.000 \\
\hline rectum & 3,967 & $70 \%$ & 1.00 & & \\
\hline sigmoid colon & 3,115 & $72 \%$ & 0.84 & $0.77-0.93$ & \\
\hline colon (except sigmoid colon) & 3,230 & $70 \%$ & 1.02 & $0.93-1.13$ & \\
\hline overlapping or unspecified & 182 & $61 \%$ & 1.17 & $0.90-1.53$ & \\
\hline Number of lymph node examined & & & & & 0.013 \\
\hline$<12$ & 3,850 & $70 \%$ & 1.00 & & \\
\hline$>=12$ & 6,644 & $72 \%$ & 0.91 & $0.84-0.98$ & \\
\hline Surgical margin & & & & & 0.000 \\
\hline$<=2 \mathrm{~mm}$ & 657 & $57 \%$ & 1.00 & & \\
\hline$>2 \mathrm{~mm},<=1 \mathrm{~cm}$ & 3,382 & $69 \%$ & 0.57 & $0.49-0.66$ & \\
\hline$>1 \mathrm{~cm}$ & 5,816 & $75 \%$ & 0.47 & $0.41-0.54$ & \\
\hline Depth of tumor invasion & & & & & 0.000 \\
\hline submucosa & 958 & $89 \%$ & 1.00 & & \\
\hline muscularis propria & 1,613 & $82 \%$ & 1.26 & $0.73-2.18$ & \\
\hline $\begin{array}{l}\text { through the muscularis propria into the } \\
\text { subserosa }\end{array}$ & 6,315 & $68 \%$ & 1.77 & $1.06-2.95$ & \\
\hline directly invades other organs or structures & 1,608 & $58 \%$ & 2.76 & $1.62-4.70$ & \\
\hline Tumor size & & & & & 0.001 \\
\hline $0-2 \mathrm{~cm}$ & 625 & $79 \%$ & 1.00 & & \\
\hline$>2.0,<=3 \mathrm{~cm}$ & 1,323 & $75 \%$ & 0.82 & $0.66-1.02$ & \\
\hline$>3.0,<=4 \mathrm{~cm}$ & 2,067 & $72 \%$ & 0.81 & $0.66-1.00$ & \\
\hline$>4.0,<=6 \mathrm{~cm}$ & 3,889 & $69 \%$ & 0.82 & $0.67-1.01$ & \\
\hline$>6.0 \mathrm{~cm}$ & 2,590 & $66 \%$ & 0.98 & $0.80-1.21$ & \\
\hline \multicolumn{6}{|l|}{ Pathology } \\
\hline adenocarcinoma & 10,016 & $71.6 \%$ & 1.00 & & 0.000 \\
\hline mucinous or signet ring cell adenocarcinoma & 478 & $62.9 \%$ & 1.50 & $1.27-1.76$ & \\
\hline TNM stage & & & & & 0.000 \\
\hline stage I & 2,114 & $88 \%$ & 1.00 & & \\
\hline stage II & 4,002 & $76 \%$ & 1.23 & $0.96-1.58$ & \\
\hline stage III & 4,378 & $56 \%$ & 3.05 & 2.39-3.89 & \\
\hline Radiotherapy & & & & & 0.004 \\
\hline no & 9,367 & $71 \%$ & 1.00 & & \\
\hline yes & 1,127 & $67 \%$ & 1.21 & $1.07-1.38$ & \\
\hline Chemotherapy & & & & & 0.000 \\
\hline no & 5,385 & $68 \%$ & 1.00 & & \\
\hline yes & 5,109 & $73 \%$ & 0.67 & $0.62-0.73$ & \\
\hline
\end{tabular}

N: number; HR: hazard ratio; Cl: confidence interval; CCl: Charlson comorbidity index; classification of TNM stage based on AJCC edition 6; *: log-rank P value 
than female patients $(56.6 \%, 5,937 / 10,494)$. Rectum was found to be the more frequent site of tumor location. About $63.3 \%(6,644 / 10,494)$ patients had no less than twelve lymph nodes examined and $59.0 \%(5,816 / 9,855)$ of pathology reports proved that surgical margin was free of tumor for more than $1 \mathrm{~cm}$ microscopically. In terms of involvement depth and tumor size, most patients $(60.2 \%$, $6,315 / 10,494)$ had cancer penetrated through the muscularis propria of colorectal wall into the subserosa and tumors grew larger than $4 \mathrm{~cm}(61.7 \%, 6,479 / 10,494)$. Variants of adenocarcinoma (such as mucinous adenocarcinoma or signet ring cell adenocarcinoma, etc.) occurred in only about $4.6 \%(478 / 10,494)$ of resected specimens. Stage III comprised of $41.7 \%(4,378 / 10,494)$ patients, followed by stage II which comprised of $38.1 \%(4,002 /$ $10,494)$ patients. Nearly half patients received chemotherapy $48.7 \%(5,109 / 10,494)$. However, much less patient underwent radiotherapy $[10.7 \%(1,127 / 10,494)]$. The duration of follow-up time was 0 - 84 months with a mean of 48.9 months. P value of log-rank test for all factors was less than 0.01 (except number of lymph node examined, $\mathrm{P}=0.013$ ) when 5 -year cancer-specific survival was designated as dependent variable. Paradoxically, the hazard ratio of radiotherapy vs. no radiotherapy was 1.21 .

We started the RPA with training sample of 5310 patients with 1,296 patients (24.4\%) died in the study period. Tumor staging (TNM system) was the most important factor that yielded a segment of 3,142 patients $(16.0 \%$ dead) with stage I \& II disease and a segment of 2,168 patients $(36.5 \%$ dead) with stage III disease $(\mathrm{p}<0.001)$. The same procedure continued following this splitting algorithm (Figure 2). In the left segment, patient's age appeared to be the strongest factor $(\mathrm{p}<0.001)$, which yielded a subgroup of 2,465 patients with age $<76.1$ years $(12.5 \%$ dead) and a subgroup of 677 patients with age $\geq$ 76.1 years $(28.7 \%$ dead) $(\mathrm{p}=0.001)$. No further split was possible in the node of stage I \& II disease and age $\geq 76.1$ years due to minimal criteria. The node with stage I \& II disease and age $<76.1$ years could be split into a subgroup of 849 patients with stage I disease $(6.8 \%$ dead) and a subgroup of 1,616 patients stage II disease (15.5\% dead) ( $\mathrm{p}<$ 0.001 ). No further split was possible in the node of stage I disease and age $<76.1$ years due to minimal criteria. But we could split the node with stage II disease and age < 76.1 years into a subgroup of 153 patients who had number of lymph nodes examined $<6(32.7 \%$ dead $)$ and a subgroup of 1,463 patients who had number of lymph nodes examined $\geq 6$ ( $13.7 \%$ dead), both of which were terminal nodes.

In the right segment, comorbidity score (CCI) seemed to be the strongest factor, by which yielded a subgroup of 166 patients with CCI $<2$ (18.1\% dead) and a subgroup of 2002 patients with $\mathrm{CCI} \geq 2$ (38.1\% alive) ( $\mathrm{p}=0.001)$. The node that patients with stage III and CCI $<2$ was a terminal node since no further split was possible. The node that patient with stage III and CCI $\geq 2$ could be further split into a subgroup of 533 patients who didn't have chemotherapy treatment $(50.1 \%$ dead) and a subgroup of 1,469 patients who ever have been treated with chemotherapy treatment (33.7\% dead), both of which were terminal nodes. The results of the RPA process were validated with a test sample of 5,184 patients with colorectal cancer which were independent of the model building training sample (Figure 3). Both results were closely correlated.

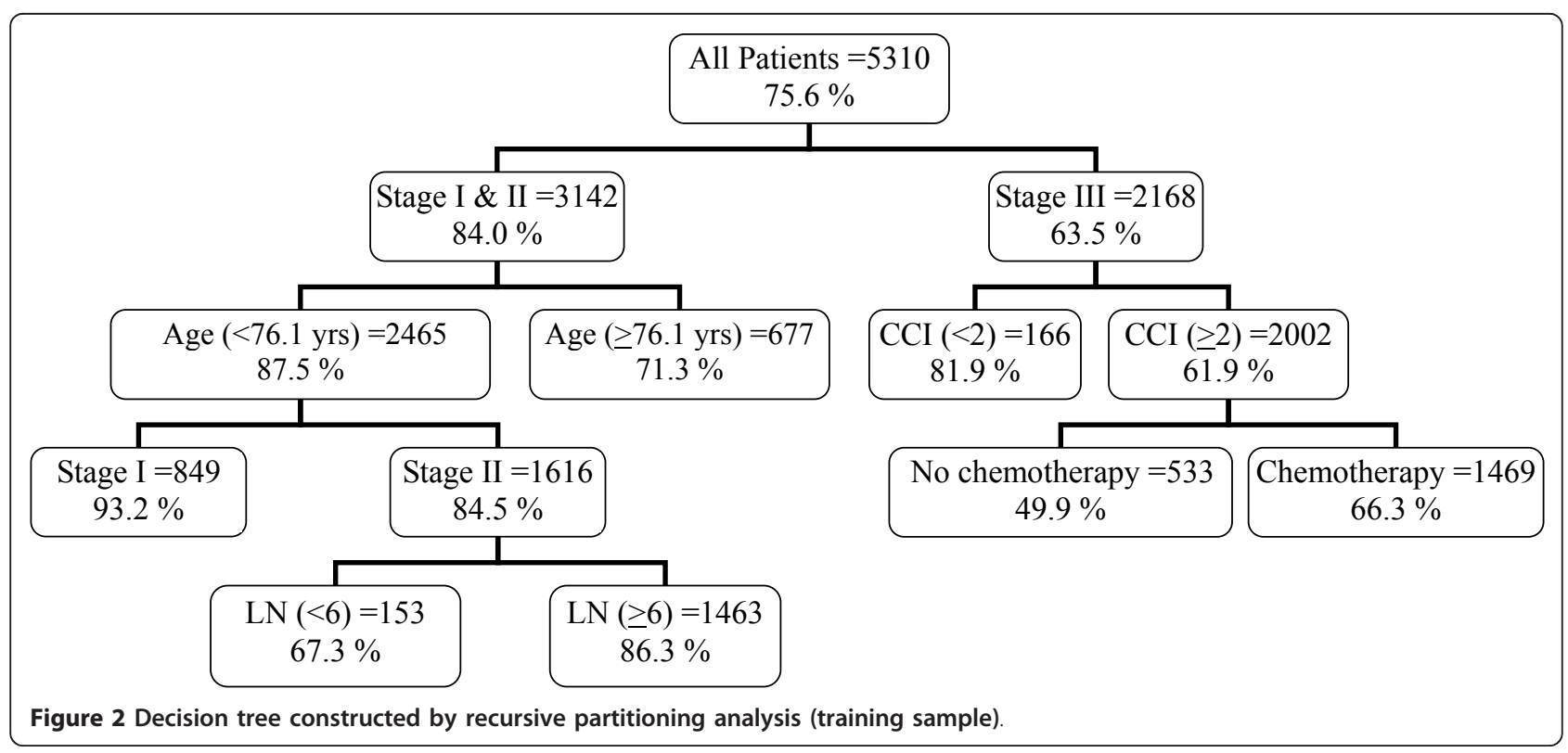




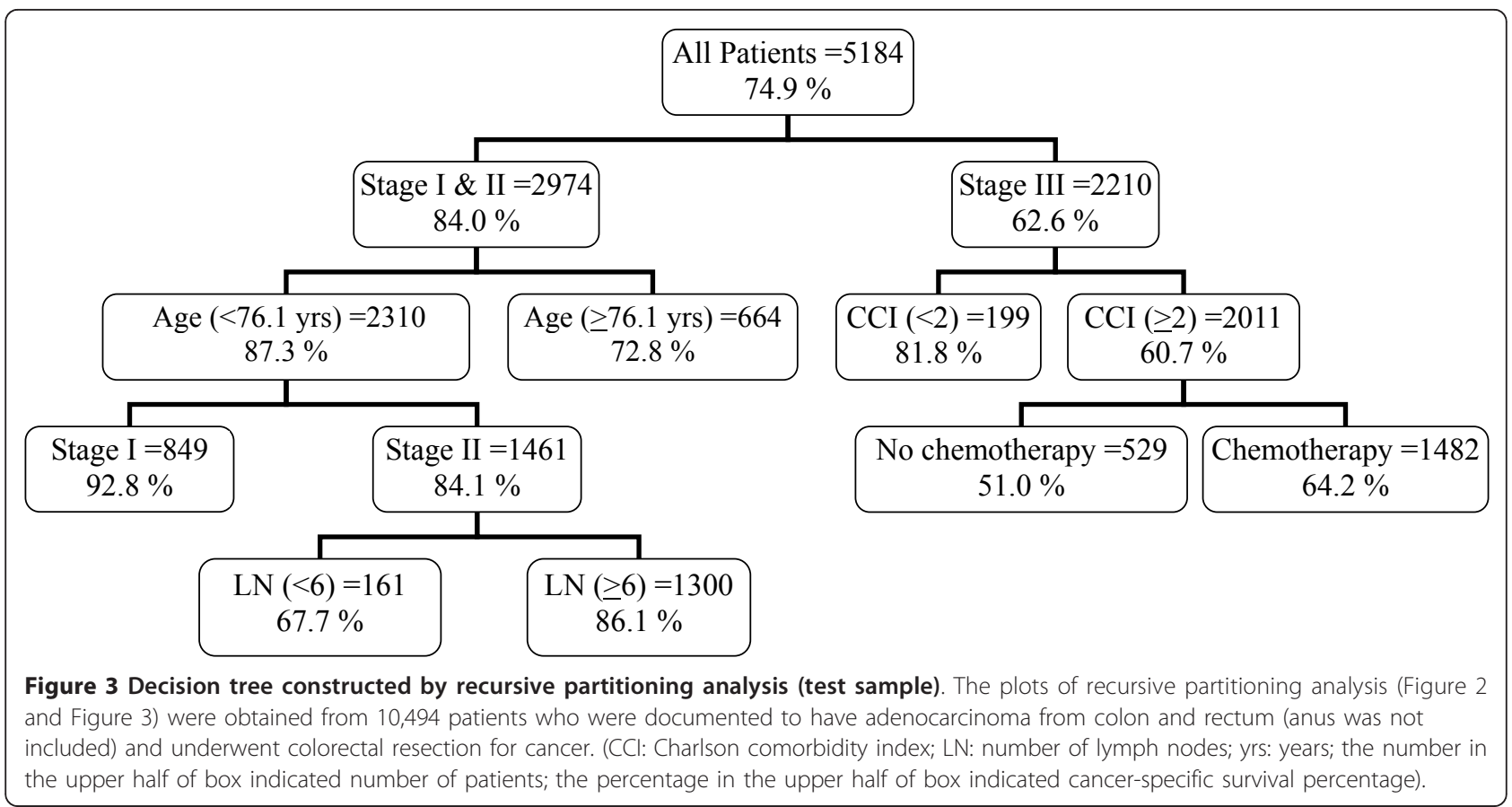

Thus five prognostic factors were identified (namely, TNM staging, age, comorbidity, number of lymph nodes examined, chemotherapy) for cancer-specific survival, resulting in seven terminal nodes. Based on mean survival time of the terminal nodes, we were able to categorized four risk groups (Table 2). Group 1 (mild risk) consisted of 1,698 patients who had stage I colorectal cancer and age $<76.1$ years (119 deaths in the study period). Group 2 (moderate risk) consisted of 3,129 patients who had stage II colorectal cancer, age $<76.1$ years and number of lymph nodes examined $\geq 6$, or stage III colorectal cancer with $\mathrm{CCI}<2$ (449 deaths in the study period). Group 3 (high risk) consisted of 4,605 patients who had stage I\&II colorectal cancer and age $\geq 76.1$ years or stage II colorectal cancer, age $<76.1$ years and number of lymph nodes examination $<6$, or stage III colorectal cancer CCI $\geq 2$ with chemotherapy (1,502 deaths in the study period). Group 4 (very high risk) consisted of 1,062 patients who had stage III colorectal cancer, CCI $\geq 2$ and without chemotherapy (525 deaths in the study period).
Cancer-specific survival analysis using Kaplan-Meier plot and log-rank test revealed significant differences among groups ( $\mathrm{p}<0.0001$, Figure 4$)$. In addition, we also utilized this RPA grouping classification to test the effects on predicting overall and progression-free survivals (3year and 5-year respectively). Results showed good discriminating capability for this grouping classification to easily predict each outcome for all endpoints (Table 3).

\section{Discussion}

This study explored the risk group definition of patients with colorectal adenocarcinoma after surgery by CRT algorithm. Risk group definition by RPA algorithm has been already proposed to predict outcomes of several benign and malignant diseases [3-5], but it was still rare for colorectal cancer as well as other gastrointestinal malignancy. For patients with rectal adenocarcinoma, Zolbec et al. ever used this technique to identify a predictive model with regard to patients' responses to preoperative radiotherapy from several molecular factors [7]. An

Table 2 Assignment of Recursive Partitioning Analysis (RPA) Groups

\begin{tabular}{llll}
\hline RPA class & Definition $(\mathbf{s})$ & Patients & Events \\
\hline Group 1 (mild risk) & stage I colorectal cancer and age $<76.1$ years, & 1,698 & 119 \\
Group 2 (moderate risk) & $\begin{array}{l}\text { stage II colorectal cancer, age }<76.1 \text { years and LN examined }>=6 \\
\text { stage III colorectal cancer, CCI }<2\end{array}$ & 3,129 & 449 \\
Group 3 (high risk) & $\begin{array}{l}\text { stage I \& II colorectal cancer, age } \geq 76.1 \text { years } \\
\text { stage II colorectal cancer, age }<76.1 \text { years and LN examined }<6\end{array}$ & 1,502 \\
Stage III colorectal cancer, CCI $>=2$, with chemotherapy & 1,062 & 525 \\
Group 4 (very high risk) & stage III colorectal cancer, CCI $>=2$, without chemotherapy & \\
\hline
\end{tabular}




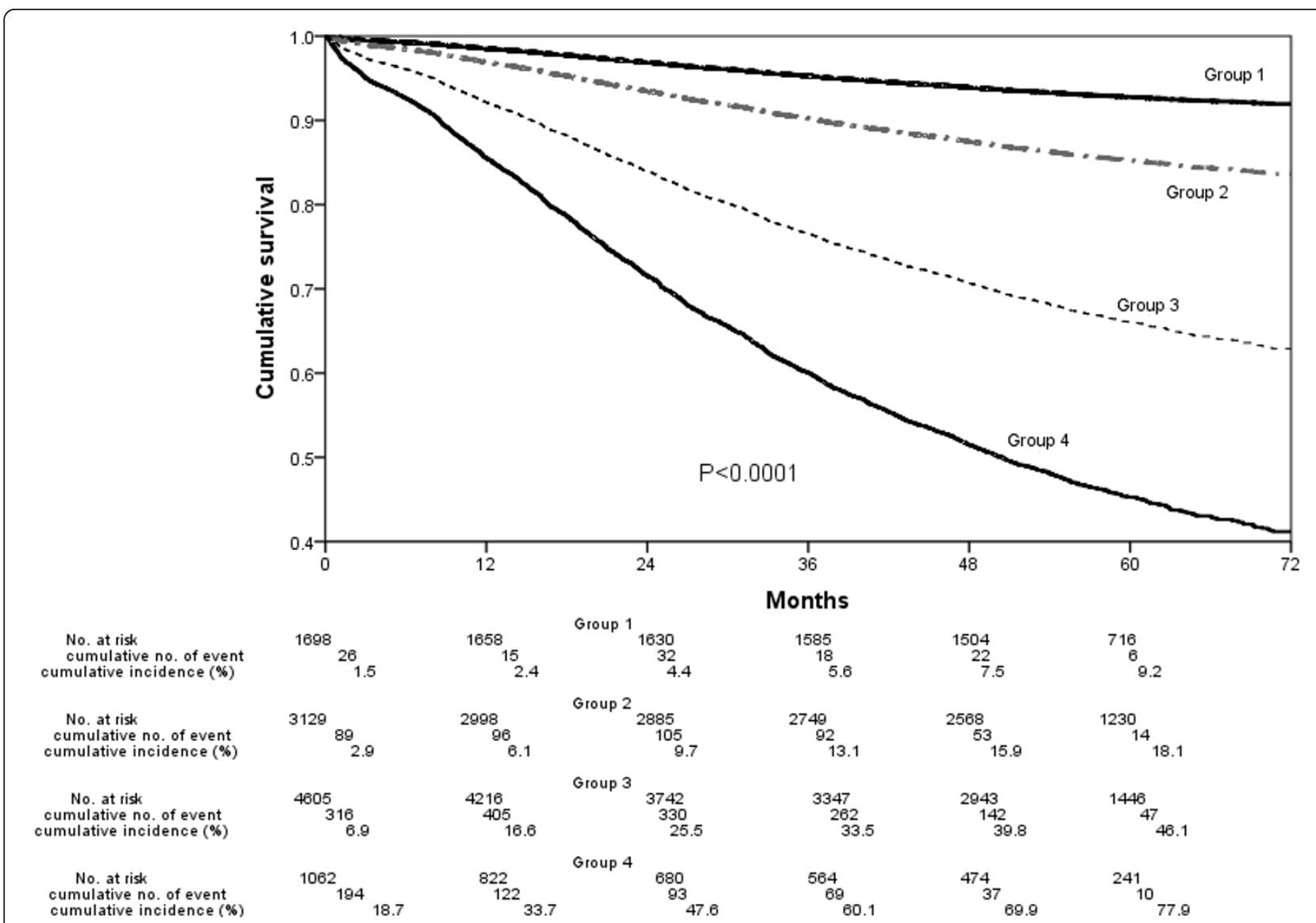

Figure 4 Survival analysis (cancer-specific survival as outcome) with Kaplan-Meier plot shows significant difference between groups ( $p$ $<0.0001$ ). (No.: number).

Table 3 The RPA groups and survival

\begin{tabular}{|c|c|c|c|c|c|}
\hline & \multicolumn{5}{|c|}{ RPA Group } \\
\hline & Group 1 & Group 2 & Group 3 & Group 4 & $P$ value \\
\hline \multicolumn{6}{|c|}{ Overall survival } \\
\hline 3-yrs (\%) & 91.5 & 84.1 & 65.7 & 45.2 & $<0.001$ \\
\hline 5-yrs (\%) & 85.6 & 78.3 & 54.8 & 35.1 & $<0.001$ \\
\hline $\mathrm{HR}$ & 1.00 & 1.70 & 4.12 & 7.88 & \\
\hline $95 \% \mathrm{Cl}$ & & $1.44-1.99$ & $3.56-4.78$ & $6.71-9.25$ & \\
\hline \multicolumn{6}{|c|}{ Progression-free survival } \\
\hline 3-yrs (\%) & 94.2 & 86.0 & 69.4 & 51.7 & $<0.001$ \\
\hline 5-yrs (\%) & 90.4 & 81.4 & 60.6 & 41.7 & $<0.001$ \\
\hline $\mathrm{HR}$ & 1.00 & 2.25 & 5.42 & 9.91 & \\
\hline $95 \% \mathrm{Cl}$ & & $1.85-2.74$ & $4.52-6.51$ & $8.16-12.11$ & \\
\hline \multicolumn{6}{|c|}{ Cancer-specific survival } \\
\hline 3-yrs (\%) & 94.5 & 87.5 & 70.5 & 52.1 & $<0.001$ \\
\hline 5-yrs (\%) & 91.1 & 83.2 & 61.9 & 43.2 & $<0.001$ \\
\hline$H R$ & 1.00 & 2.13 & 5.52 & 10.56 & \\
\hline $95 \% \mathrm{Cl}$ & & $1.74-2.60$ & $4.58-6.66$ & $8.66-12.90$ & \\
\hline
\end{tabular}

RPA: recursive partitioning analysis; yrs: years; HR: hazard ratio; Cl: confidence interval 
empirically useful model that predict survival outcome credibly allows important clinical implication for patients, surgeons and stakeholders to make appropriate treatment decisions. In this study, the results yielded five prognostic factors, which could be further used to define four risk groups. These four RPA groups not only differed significantly with regard to cancer-specific survival but also provided prognostic significance concerning with progression-free survival as well as overall survival.

Traditionally, a prognostic or risk factor can be easily identified through univariate or multivariate analyses from Cox proportional hazards model as Table 1 demonstrated in this study. It may be possible to predict a survival probability of a certain prognostic factor through Cox proportional hazards model, however, it is always difficult to interpret or predict a patient's cumulative risk for a given set of prognostic factors. In actual daily practice, patients usually present with a lot of prognostic or risk factors, especially when there are interaction terms involved. Hence, provision a useful and informative risk group definition for empirical use is a tough task. Furthermore, the cut-off values of defining risk groups in the hazard model often are arbitrary [5]. Theoretically, multivariate regression model offers hazard ratio for entire population while RPA allows different prognostic factors for different branch of the tree model. Therefore, RPA is a better statistic methodology when there are interactions between prognostic (or risk) factors.

Several studies have documented the association between patient attribute, tumor characteristics, process (treatment), pathological finding and the survival of colorectal cancer. Prognostic or risk factors frequently observed for survival are gender [8,9], age [9], comorbidity [10], number of lymph nodes examined [11-13], tumor size [14], tumor TNM staging [12,15], depth of tumor invasion [16], safety surgical margin [17], chemotherapy [18-21] and radiotherapy [22]. Except radiotherapy, the prognostic significance of these variables was confirmed in our study by Cox proportional hazard model. However, the impact of predictability of radiotherapy with regard to cancer-specific survival in the hazard model, estimated through all colorectal cohort (not stage III rectal cancer only), may decreased even in the opposite direction as described in the Method section.

Tumor stage was still the most important prognosticator throughout this tree-structured model for cancer-specific survival of patients with colorectal cancer. Patients with stage III disease survived much shorter than patient with stage I or II disease. For those patients with negative lymph node status (stage I \& II disease) in the left segment of Figure 2, we identified that age as well as number of lymph nodes examined were associated with patients' long-term survival. For those patients with positive lymph node status (stage III disease only) in the right segment, we identified comorbidity index and chemotherapy were associated with patients' long-term survival. In other words, age was a prognostic factor for patient with stage I disease; while age and harvest lymph nodes $\geq 6$ might predict long-term survival for patient with stage II disease. Comorbidity index and chemotherapy were the most important prognostic factors for patient with stage III disease. We noted in the subset of patients with stage III disease and $\mathrm{CCI} \geq 2$, chemotherapy had been identified as one of the most important prognostic factors postoperatively for survival after colorectal surgery. The benefit was about 15\% improvement in survival. Compared to prior report, Mamounas et al. had found chemotherapy resulted in an increase of $18 \%$ survival in overall survival for stage III colon cancers [23]. In a meta-analysis investigating the usage of chemotherapy, Benson et al. had discovered the $14 \%$ decrease in 5 -year mortality rate for stage II colon cancer patients who received 5-FU based chemotherapy [24]. However, our data failed to prove this advantage for patient with stage II disease.

No matter where the tumor located (colon or rectum), comorbidity exhibited an important predictive value for long-term survival. Our results echoed the study of Klabunde et al., who had demonstrated that comorbidity status can predict long-term survival of patients with four types of malignancy including colorectal cancer [10]. Originally developed by epidemiologists to predict hospital mortality of breast cancer, comorbidity seems to be useful in predicting patient's long-term survival with regard to coexisting medical conditions and malignancies. Our results also elucidated the importance of lymph node harvest of surgery for colorectal cancer, which was recently endorsed or adopted by several academic societies and healthcare management organizations to be a quality metric for colorectal cancer care [25]. Although the number of six lymph nodes deriving by CRT algorithm from our study was different from their minimum requirement of twelve lymph nodes, this might highlight us that harvest enough lymph nodes was an important prognosticator for patients with stage II disease. Several authors suggested that understaging might account for the underling mechanism which explained why inadequate lymph node yield would lead to decreased patients' survival $[26,27]$. Another unexpected finding in this survival tree model was radiotherapy. Adjuvant therapy (chemotherapy and radiotherapy) had been advocated for certain group of patients with colorectal cancer by several authors as alternatives to improve patient's outcome [28]. While chemotherapy could predict patients' long-term survival in the model, radiotherapy failed to show its importance in this respect. The small volume of patients treated with radiotherapy and the default setting of RPA algorithm might somewhat explain why radiotherapy didn't enter in this model. 
There were several forms of survival that could be used to evaluate the consequences of patients underwent certain treatment procedures or interventions, including overall survival, progression-free survival and diseasespecific survival [5]. Perhaps one may question why we used cancer-specific survival as the outcome determinant of the model building of RPA in the analysis. Overall survival might be the most frequent used form of survival for its information easily collected. But overall survival focused on patients' survival during a certain period of time regardless of patients' reasons of death being cancer-related condition or not, which probably not truthfully reflect the consequences or outcomes of an intervention given to a specific disease such as cancer. For patients with cancer, especially colorectal cancer (geriatric patients were not uncommon), the cause of mortality might not actually related to colorectal cancer or liver metastasis. Causes of death other than diseasespecific cancer death in this study included accident (or suicide), old age, other cancer, diabetes, cardiovascular accident and asthma attack, etc. So we did think the optimum candidate of outcome variable in the model building process in this study was cancer-specific survival.

This study has two contributions toward predicting outcomes after surgical intervention of colorectal cancer. First, we tried to apply classification and regression model for evaluating treatments of colorectal cancer patients and to define risk groups relating to long-term survival. To the best our knowledge, this is the first report regarding treestructured survival analysis for colorectal cancer surgery using population-based data. Second, we sought to present outcomes in three forms (overall, progression-free and disease-specific survival) simultaneously, which had rarely been shown in related literature.

Several limitations of this method in this study should be mentioned. First, we did not include any molecular marker in RPA process due to unavailability of data, which beyond the range that our population-based data regularly collected. Second, although we try to find out risk group definition at national level, this was not really a $100 \%$ nationwide database of all colorectal cancer patients. However, we thought this database (around 60\% of all colorectal cancer annually) literally enough in representing the daily situation what we encountered everyday. Third, we're not sure that the findings from our population-based dataset could be extrapolated to other health system where multiple factors might not be the same. After all, the healthcare insurance system in Taiwan is a single-payer system.

\section{Conclusions}

In conclusion, our study demonstrated the utility of classification and regression tree in patients with colorectal adenocarcinoma disease treated with colorectal resection. The risk groups defined by RPA algorithm with regard to cancer-specific survival could also predict 5 -year overall and progression-free survival. RPA could be used as an alternative method to study prognosis of cancer. In the future, it may require more studies in other healthcare systems to validate the utility of RPA in colorectal cancer care.

\section{Acknowledgements}

We thank to Bureau of Health Promotion, Department of Health in Taiwan for providing data for analysis.

\section{Author details}

${ }^{1}$ Graduate Institute of Health Policy and Management, College of Public Health, National Taiwan University, Taipei, Taiwan. ${ }^{2}$ Department of General Surgery, Zhong-Xing Branch, Taipei City Hospital, Taipei, Taiwan.

${ }^{3}$ Department of General Surgery, National Taiwan University Hospital, Taipei, Taiwan. ${ }^{4}$ Department of Ophthalmology, HepingFuyou Branch, Taipei City Hospital, Taipei, Taiwan. ${ }^{5}$ Department of Surgery, Taipei Branch, Buddhist Tzu Chi General Hospital, Taipei, Taiwan. ${ }^{6}$ Graduate Institute of Epidemiology and Preventive Medicine, College of Public Health, National Taiwan University, Taipei, Taiwan

\section{Authors' contributions}

LJC designed methods, analyzed data, and revised the manuscript. YJC (YunJau Chang) analyzed data, interpreted the results and wrote the manuscript. YJC (Yao-Jen Chang) partook in the interpretation of the results and discussion. KPC and MSL participated in data collection and reviewed the manuscript. All authors read and approved the final manuscript.

\section{Competing interests}

The authors declare that they have no competing interests.

Received: 16 June 2011 Accepted: 3 January 2012

Published: 3 January 2012

\section{References}

1. Chung KP, Chang YJ, Lai MS, Kuo RN, Cheng SH, Chen LT, Tang R, Liu TW, Shieh MJ: Is quality of colorectal cancer care good enough? Core measures development and its application for comparing hospitals in Taiwan. BMC Health Serv Res 2010, 10:27.

2. Schneider EC, Epstein AM, Malin JL, Kahn KL, Emanuel EJ: Developing a system to assess the quality of cancer care: ASCO's national initiative on cancer care quality. J Clin Oncol 2004, 22(15):2985-2991.

3. Park CK, Lee SH, Han JH, Kim CY, Kim DW, Paek SH, Kim DG, Heo DS,

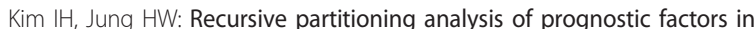
WHO grade III glioma patients treated with radiotherapy or radiotherapy plus chemotherapy. BMC Cancer 2009, 9:450.

4. Lamborn KR, Chang SM, Prados MD: Prognostic factors for survival of patients with glioblastoma: recursive partitioning analysis. Neuro Oncol 2004, 6(3):227-235

5. Langendijk JA, Slotman BJ, van der Waal I, Doornaert P, Berkof J, Leemans CR: Risk-group definition by recursive partitioning analysis of patients with squamous cell head and neck carcinoma treated with surgery and postoperative radiotherapy. Cancer 2005, 104(7):1408-1417.

6. Deyo RA, Cherkin DC, Ciol MA: Adapting a clinical comorbidity index for use with ICD-9-CM administrative databases. J Clin Epidemiol 1992, 45(6):613-619.

7. Zlobec I, Steele R, Nigam N, Compton CC: A predictive model of rectal tumor response to preoperative radiotherapy using classification and regression tree methods. Clin Cancer Res 2005, 11(15):5440-5443.

8. Hendifar A, Yang D, Lenz F, Lurje G, Pohl A, Lenz C, Ning Y, Zhang W, Lenz HJ: Gender disparities in metastatic colorectal cancer survival. Clin Cancer Res 2009, 15(20):6391-6397.

9. Jessup JM, Stewart A, Greene FL, Minsky BD: Adjuvant chemotherapy for stage III colon cancer - Implications of race/ethnicity, age, and differentiation. JAMA 2005, 294(21):2703-2711. 
10. Klabunde CN, Legler JM, Warren $J$, Baldwin LM, Schrag D: A refined comorbidity measurement algorithm for claims-based studies of breast, prostate, colorectal, and lung cancer patients. Annals of Epidemiology 2007, 17(8):584-590.

11. Chen SL, Bilchik AJ: More extensive nodal dissection improves survival for stages I to III of colon cancer - a population-based study. Ann Surg 2006, 244(4):602-610.

12. Namm J, Ng M, Roy-Chowdhury S, Morgan JW, Lum SS, Wong JH: Quantitating the impact of stage migration on staging accuracy in colorectal cancer. J Am Coll Surg 2008, 207(6):882-887.

13. Chang YJ, Chen LJ, Chang YJ, Chung KP, Lai MS: Application of Propensity Score Model to Examine The Prognostic Significance of Lymph Node Number as a Care Quality Indicator. Surgl Oncol 2012.

14. Mehrkhani F, Nasiri S, Donboli K, Meysamie A, Hedayat A: Prognostic factors in survival of colorectal cancer patients after surgery. Colorectal Dis 2009, 11(2):157-161.

15. Staib L, Link KH, Blatz A, Beger HG: Surgery of colorectal cancer: Surgical morbidity and five- and ten-year results in 2400 patients Monoinstitutional experience. World J Surg 2002, 26(1):59-66.

16. Gunderson LL, Sargent DJ, Tepper JE, Wolmark N, O'Connell MJ, Begovic M, Allmer C, Colangelo L, Smalley SR, Haller DG, et al: Impact of T and N stage and treatment on survival and relapse in adjuvant rectal cancer: $\mathrm{A}$ pooled analysis. J Clin Oncol 2004, 22(10):1785-1796

17. Kelly SB, Mills SJ, Bradburn DM, Ratcliffe AA, Borowski DW: Effect of the circumferential resection margin on survival following rectal cancer surgery. Br J Surg 2011.

18. Martenson JA, Willett CG, Sargent DJ, Mailliard JA, Donohue JH, Gunderson LL, Thomas CR, Fisher B, Benson AB, Myerson R, et al: Phase III study of adjuvant chemotherapy and radiation therapy compared with chemotherapy alone in the surgical adjuvant treatment of colon cancer: Results of intergroup protocol 0130. J Clin Oncol 2004, 22(16):3277-3283.

19. Cunningham D, Humblet $Y$, Siena S, Khayat D, Bleiberg H, Santoro A, Bets D, Mueser M, Harstrick A, Verslype C, et al: Cetuximab monotherapy and cetuximab plus irinotecan in irinotecan-refractory metastatic colorectal cancer. N Engl J Med 2004, 351(4):337-345.

20. Chen HX, Mooney M, Boron M, Vena D, Mosby K, Grochow L, Jaffe C Rubinstein L, Zwiebel J, Kaplan RS: Phase II multicenter trial of bevacizumab plus fluorouracil and leucovorin in patients with advanced refractory colorectal cancer: An NCl Treatment Referral Center trial TRC0301. J Clin Oncol 2006, 24(21):3354-3360.

21. Sanoff HK, Sargent DJ, Green EM, McLeod HL, Goldberg RM: Racial Differences in Advanced Colorectal Cancer Outcomes and Pharmacogenetics: A Subgroup Analysis of a Large Randomized Clinical Trial. Amer Soc Clinical Oncology 2009 2009, 4109-4115.

22. Bosset JF, Collette $L$, Calais $G$, Mineur $L$, Maingon P, Radosevic-Jelic L, Daban A, Bardet E, Beny A, Ollier J: Chemotherapy with preoperative radiotherapy in rectal cancer. $N$ Engl J Med 2006, 355(11):1114-1123.

23. Mamounas E, Wieand S, Wolmark N, Bear HD, Atkins JN, Song K, Jones J, Rockette $\mathrm{H}$ : Comparative efficacy of adjuvant chemotherapy in patients with Dukes' B versus Dukes' C colon cancer: results from four National Surgical Adjuvant Breast and Bowel Project adjuvant studies (C-01, C-02, C-03, and C-04). J Clin Oncol 1999, 17(5):1349-1355.

24. Benson AB, Schrag D, Somerfield MR, Cohen AM, Figueredo AT, Flynn PJ, Krzyzanowska MK, Maroun J, McAllister P, Van Cutsem E, et al: American society of clinical oncology recommendations on adjuvant chemotherapy for stage II colon cancer. J Clin Oncol 2004 22(16):3408-3419.

25. Bilimoria $K Y$, Stewart AK, Edge SB, Ko CY: Lymph node examination rate, survival rate, and quality of care in colon cancer. JAMA 2008, 299(8):896-896.

26. Derwinger K, Carlsson G, Gustavsson B: Stage migration in colorectal cancer related to improved lymph node assessment. Eur J Surg Oncol 2007, 33(7):849-853.

27. George S, Primrose J, Talbot R, Smith J, Mullee M, Bailey D, du Boulay C, Jordan H: Will Rogers revisited: prospective observational study of survival of 3592 patients with colorectal cancer according to number of nodes examined by pathologists. Br J Cancer 2006, 95(7):841-847.

28. Scott N: Radiotherapy and rectal cancer. J Pathol 2002, 197(1):4-5.

\section{Pre-publication history}

The pre-publication history for this paper can be accessed here: http://www.biomedcentral.com/1471-2288/12/2/prepub

doi:10.1186/1471-2288-12-2

Cite this article as: Chang et al:: Risk Groups Defined by Recursive Partitioning Analysis of Patients with Colorectal Adenocarcinoma Treated with Colorectal Resection. BMC Medical Research Methodology 2012 12:2.

\section{Submit your next manuscript to BioMed Central and take full advantage of:}

- Convenient online submission

- Thorough peer review

- No space constraints or color figure charges

- Immediate publication on acceptance

- Inclusion in PubMed, CAS, Scopus and Google Scholar

- Research which is freely available for redistribution

Submit your manuscript at www.biomedcentral.com/submit
Ciomed Central 